\title{
Influence of dichloromethylene bisphosphonate on the in vitro phagocytosis of hydroxyapatite particles by rat peritoneal exudate cells: an electron microscopic and chemiluminescence study
}

\author{
P M Hyvönen, M J Kowolik
}

\begin{abstract}
Transmission electron microscopy and standard chemiluminescence assays were used to investigate the in vivo effect of dichloromethylene bisphosphonate (clodronate) on the phagocytosis of pure hydroxyapatite particles by rat peritoneal macrophages and the production of chemiluminescence by the peritoneal exudate cells. Hydroxyapatite (control) and a hydroxyapatite/clodronate suspension $(28 \mu \mathrm{mol}$ clodronate per gram of hydroxyapatite, experimental) were injected into the peritoneum of rats, the clodronate dose being $10 \mu \mathrm{g} / \mathrm{kg}$. Macrophages were harvested at $12,24,48$, and 96 hours after injection and the particle phagocytosis was assessed by transmission electron microscopy. Hydroxyapatite alone was completely phagocytosed by 24 hours and hydroxyapatite reacted with clodronate was completely phagocytosed by $\mathbf{4 8}$ hours. From $\mathbf{4 8}$ hours onwards hydroxyapatite particle dissolution was observed in the phagosomes of cells in the two groups. At 48 hours the chemiluminescence produced by the peritoneal exudate cells was also measured. Clodronate and clodronate/hydroxyapatite enhanced cell activity on subsequent challenge with phorbol myristate acetate or zymosan. Clodronate seemed to exhibit an inhibitory effect on the phagocytic activity and an enhancement of the chemiluminescence production by the cells in this model, indicating that it was modifying the inflammatory cell response.
\end{abstract}

Geminal bisphosphonates are a group of drugs of particular interest because of their ability to modify calcium metabolism. This effect results from a decrease in the solubility of hydroxyapatite in vitro and by cell mediated mechanisms in vivo. ${ }^{2}$ In clinical treatment, bisphosphonates have been used to treat metastatic bone disease, ${ }^{3}$ hypercalcaemia due to malignancy, ${ }^{45}$ and Paget's disease. ${ }^{6}$ At the cellular level, the mode of action is not fully understood, but it is known that one of the target cells is the osteoclast, towards which dichloromethylene bisphosphonate (clodronate), at least, is toxic. ${ }^{2}$ Clodronate is highly soluble in water and shows a strong affinity for calcified tissue. ${ }^{7}$ In an attempt to clarify the pharmacological mechanisms operating, a number of experimental models have been used. ${ }^{8}$ It has been shown in an in vivo experiment that clodronate also has antiinflammatory properties. ${ }^{9}$
Hydroxyapatite crystals have been found in the joint effusions of patients with rheumatoid arthritis, ${ }^{10}$ and macrophages remove these crystals from the joint cavities. " Macrophages, in general, are immunoregulatory and inflammatory cells, the latter function being characterised by their phagocytic capacity. Phagocytosis is the primordial function of neutrophil granulocytes and the two cell types comprise the host's phagocytes. They have been found in the peritoneal cell exudate of many laboratory animals. ${ }^{12}$ The membrane stimulation of inflammatory phagocytes can be measured by chemiluminescence, that is, the light generated by the oxygen dependent microbicidal system. The chemiluminescence assay is a measure of the rate of liberation of reactive oxygen species by macrophages and granulocytes; these reactive oxygen species may contribute to tissue damage in inflammatory diseases. ${ }^{13}$ Different pathways of light production can be identified: the myeloperoxide mediated reaction can be identified by stimulating cells with zymosan and using luminol as an intermediate; superoxide anion dependent chemiluminescence can be measured by stimulating cells with phorbol myristate acetate and augmenting the light output with lucigenin. ${ }^{14}$ Neutrophil granulocytes in most animal species can be strongly activated through these two pathways, whereas monocytes and macrophages have little or no myeloperoxidase.

On the basis of the reports summarised above, we decided to investigate, by transmission electron microscopy, whether the simultaneous presence of clodronate with pure hydroxyapatite particles influences the phagocytosis of these by rat peritoneal macrophages in vivo. We also wanted to see whether, in this experimental system, there would be an effect on the liberation of reactive oxygen species by these cells, as measured by chemiluminescence.

\section{Materials and methods}

HYDROXYAPATITE AND CLODRONATE

Chemically pure, synthetically manufactured hydroxyapatite (British Charcoals and MacDonald) with a mean particle size of $5 \mu \mathrm{m}$ was used.

Clodronate (Leiras Pharmaceuticals) was dissolved in calcium and magnesium free phosphate buffered saline (PBS), $\mathrm{pH} 7 \cdot 2$, at a working concentration of $2 \mathrm{mg} / \mathrm{ml}$. A hydroxyapatite/ clodronate combination was prepared by allow- 
ing the two compounds to react in the ratio of 1 g hydroxyapatite to $28 \mu \mathrm{mol}$ clodronate for a minimum of 42 hours. $^{7}$

EXPERIMENTAL ANIMALS

Healthy, adult Wistar SPF rats, in groups of 25 (males, transmission electron microscopy experiments) and 22 (eight males and 14 females, chemiluminescence experiments) animals were used.

\section{EXPERIMENTAL PROTOCOL}

The peritoneal cavity of each experimental animal was injected according to one of the following protocols: $(a)$ PBS, control group; $(b)$ clodronate alone, drug concentration as above, dose $10 \mathrm{mg} / \mathrm{kg}$ body weight; (c) hydroxyapatite suspension alone at $84.55 \mathrm{mg} / \mathrm{ml}$; (d) hydroxyapatite/clodronate combination giving the same concentrations of agents as in $b$ and $c$.

Intraperitoneal incubation was allowed to proceed for $12,24,48,72$, or 94 hours.

The chemiluminescence experiments were performed at 48 hours after injection only. In addition, the drug at $30 \mathrm{mg} / \mathrm{kg}$ alone and the hydroxyapatite/clodronate combination were tested for their influence on chemiluminescence. The volume injected was consistently $10 \mathrm{mg} / \mathrm{kg}$.

\section{HARVESTING AND COLLECTION OF PERITONEAL}

CELLS

The animals were anaesthetised with $6 \cdot 1 \%$ thiopental solution (Hypnostan, Leiras), the minimum dose being $2 \mathrm{ml}$. Abdominal skin and muscles were reflected and the peritoneal wall exposed. One catheter (Venflon No 2, Viggo) was inserted into the peritoneal cavity at the groin and another symmetrically on the opposite side. Via one catheter, $20 \mathrm{ml}$ of sterile PBS was injected into the peritoneum and after two minutes of gentle massage the stopper was removed from the opposite catheter. The fluid was allowed to drip into a $50 \mathrm{ml}$ polyethylene tube (Costar No 3350) in ice. PBS was added continuously via the first catheter and a total of $50-100 \mathrm{ml}$ of lavage fluid was collected. This was centrifuged at $380 \mathrm{~g}$ for 10 minutes, after which any red blood cells were removed by hypotonic lysis with $0.87 \%$ ammonium chloride solution for 10 minutes. After further centrifugation the cells were resuspended in PBS and counted in a Coulter counter prior to the assessment of cell viability by trypan blue dye exclusion.

The animals were killed after cell harvesting by cervical dislocation. All animal procedures were in compliance with the Declaration of Helsinki.

PREPARATION OF SPECIMENS FOR TRANSMISSION ELECTRON MICROSCOPY

A cell pellet was formed by centrifugation at 380 $g$ for 10 minutes, and prefixed in $2 \%$ glutaraldehyde solution for two hours. The pellet was then washed for 10 minutes in PBS and postfixed in $1 \%$ osmium tetroxide for one hour.
Thereafter the pellet was washed and dehydrated in increasing concentrations of alcohol and finally in propylene oxide. The specimen was then embedded in epoxy resin (LX-112, Ladd Research Industries) by a standard procedure. Ultrathin sections were cut with an LKB Ultramicrotome and stained with Ultrostain 1 (9001 3710) for 20 minutes and Ultrostain 2 (9001 3711) for two minutes, at room temperature (both stains from LKB). Finally, the specimens were mounted on copper grids, sputtered with carbon and viewed with a Jeol JEM-1200 EX transmission electron microscope.

For each experiment at each time point a minimum of 50 fields was examined to assess cell morphology and phagocytosis.

\section{MEASUREMENT OF CHEMILUMINESCENCE}

The concentration of cells was adjusted to $1 \times 10^{7}$ cells per $\mathrm{ml}$ for the chemiluminescence experiments.

To test the activation of the superoxide anion pathway, $500 \mu \mathrm{l}$ of cell suspension was placed in the reaction cuvette, followed by $200 \mu$ l lucigenin $\left(1 \times 10^{-3} \mathrm{M}\right.$, Sigma Chemicals) and $200 \mu \mathrm{l}$ phorbol myristate acetate as stimulant (2.5 $\mu \mathrm{g} / \mathrm{ml}$, Sigma Chemicals).

The resultant chemiluminescence was measured at $37^{\circ} \mathrm{C}$ in an LKB 1250 luminometer, recorded as millivolts and calculated per $1 \times 10^{6}$ cells. From the curves generated the maximum potential was recorded. In addition, the area under the curve was quantitated between the start of the experiment and the point at which the potential had declined to $50 \%$ of the peak value. This was achieved by digitising the data from the curves using a Kontron image analysis system (IBAS 1).

To assess any contribution to the production of chemiluminescence by the myeloperoxidase mediated pathway, $200 \mu$ l luminol $\left(5 \times 10^{-4} \mathrm{M}\right)$ and $200 \mu \mathrm{l}$ serum treated zymosan $(10 \mathrm{mg} / \mathrm{ml})$ were added to the reaction vial.

The two chemiluminescence systems were studied alone and consecutively in the cell batch experiment. For example, luminol and zymosan were added to the reaction cuvette after the chemiluminescence produced by the lucigenin/ phorbol myristate acetate regimen had subsided to $50 \%$ of the peak potential and vice versa. At least one duplicate experiment was conducted on cells collected from each animal.

\section{STATISTICAL ANALYSIS}

Student's $t$ test was used for statistical analysis.

\section{Results}

Cell viability in the lavage fluid was consistently greater than $96 \%$, as determined by the trypan blue dye exclusion test.

\section{TRANSMISSION ELECTRON MICROSCOPY} EXPERIMENTS

Phagocytosis and morphology were assessed only for the macrophages. These made up approximately $90 \%$ of the exudate cells, the rest of the cells being mainly granulocytes. 


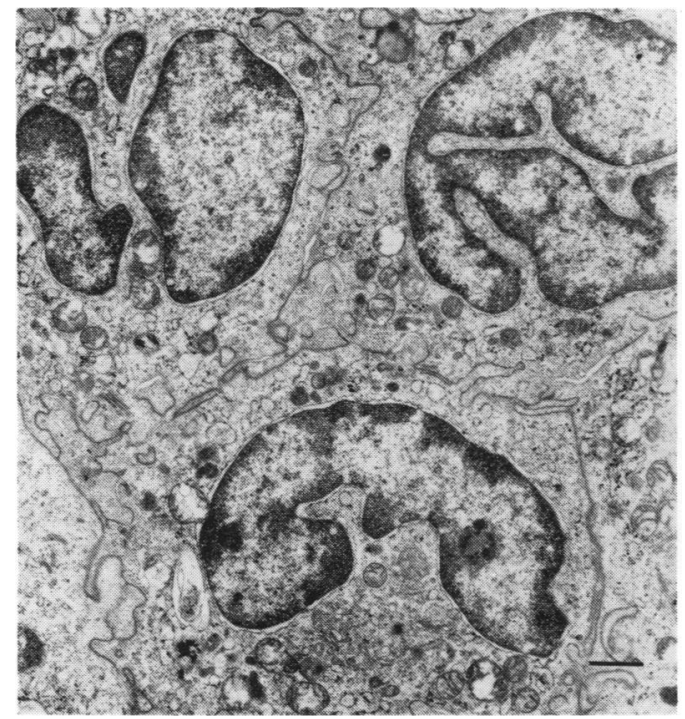

Figure 1 Control cell at 12 hours after injection. Bar $=1 \mu \mathrm{m}$.
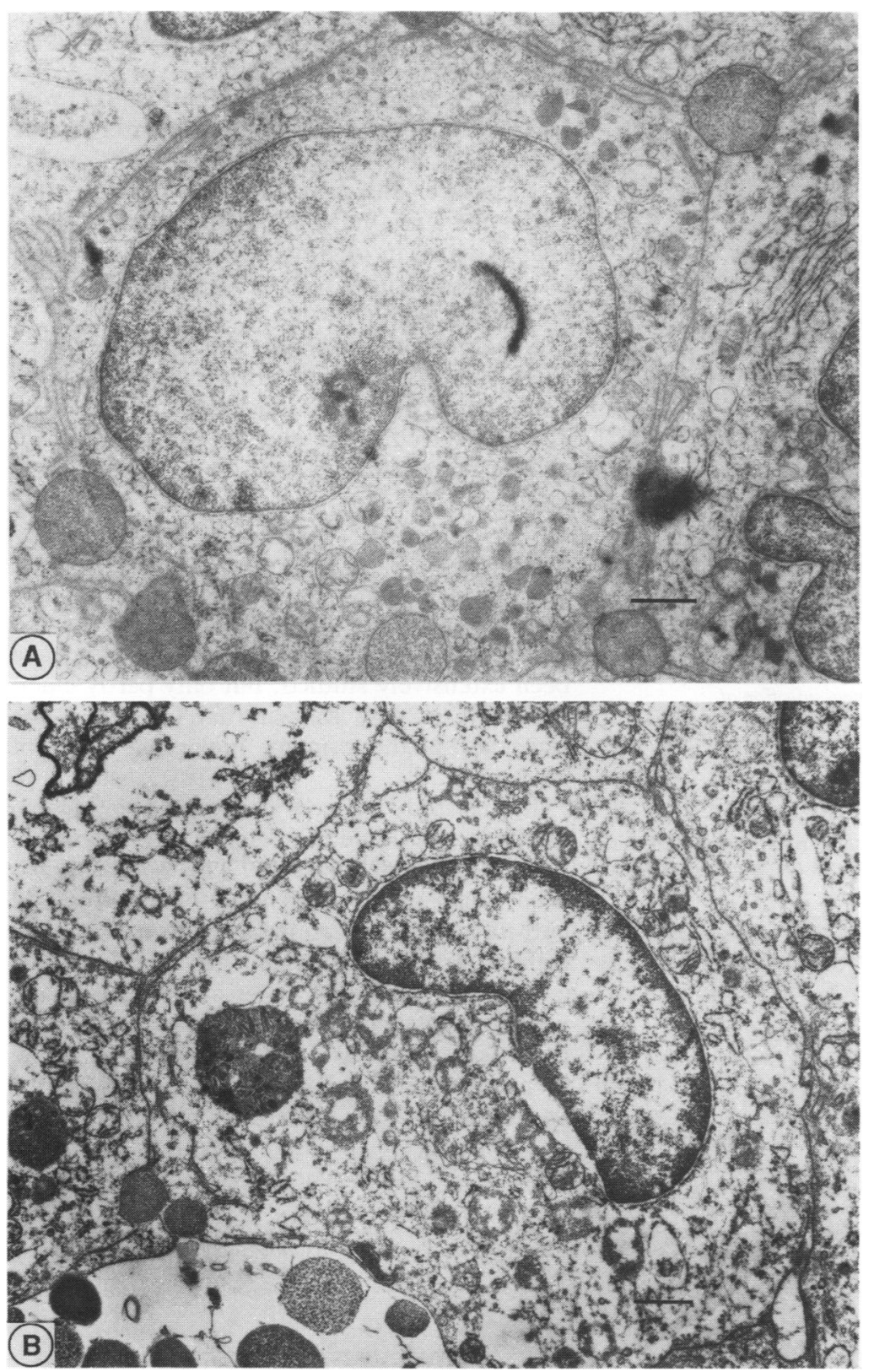

Figure 2 (A) Rat peritoneal macrophages after intraperitoneal clodronate injection at 48 hours. Bar = l um. (B) Rat peritoneal macrophages after intraperitoneal clodronate injection at 96 hours. Bar $=1$ l $\mu \mathrm{m}$.
Figure 1 shows that the cells collected from the control animals showed good general morphology and cell organelles.

\section{Effect of clodronate}

Initially, the cell morphology seemed to be unaffected by the presence of clodronate. Figure $2 \mathrm{~A}$ shows that until 24 hours after injection the cells from the control and injected animals looked similar. Figure 2B shows that macrophages collected later showed increasing heterogeneity of the cytoplasm, but mitochondria were seen.

\section{Phagocytosis of hydroxyapatite particles}

After 12 hours of incubation there was evidence of intracellular hydroxyapatite, but at this time particles were also regularly observed extracellularly. All hydroxyapatite particles had been phagocytosed by 24 hours as none was seen extracellularly. Figure 3 shows that in several 72 and 96 hour specimens disintegration of intravacuolar hydroxyapatite particles was observed. This was accompanied by vacuolisation of the cytoplasm and degeneration of cellular morphology (fig 3B).

Phagocytosis of hydroxyapatite particles reacted with clodronate

Phagocytosis was frequently seen from 12 hours onwards. By 24 hours most but not all hydroxyapatite particles were intracellular, and by 48 hours no particles remained outside the cells. Hydroxyapatite particle disintegration and crystal dissolution were seen only rarely at 48 hours, but in numerous cells in 72 and 96 hour experiments (figs 4A and B). The frequency or extent of particle dissolution was not quantitated. In the presence of phagocytosis, good cell morphology was preserved during the incubation. Figure 4B shows that at 96 hours cytoplasm had degenerated less than in cells containing plain hydroxyapatite, and morphologically distinct mitochondria were seen. The situation was similar at 72 hours. Figure 4C shows an example of more advanced hydroxyapatite particle dissolution at 96 hours.

\section{CHEMILUMINESCENCE EXPERIMENTS}

Chemiluminescence assays were performed for the peritoneal exudate cells, which consisted of two cell types capable of light generation: macrophages and polymorphonuclear neutrophil granulocytes.

\section{Pattern of chemiluminescence production}

In all experimental systems chemiluminescence was produced, showing cell viability and activation. A total of 45 experiments was conducted, and a minimum of four tests was performed per experimental group. Figures 5-8 show examples of the pattern of chemiluminescence kinetics, the voltage values on the vertical axis being for $5 \times 10^{6}$ cells.

Figure 5 shows a typical example of phorbol 


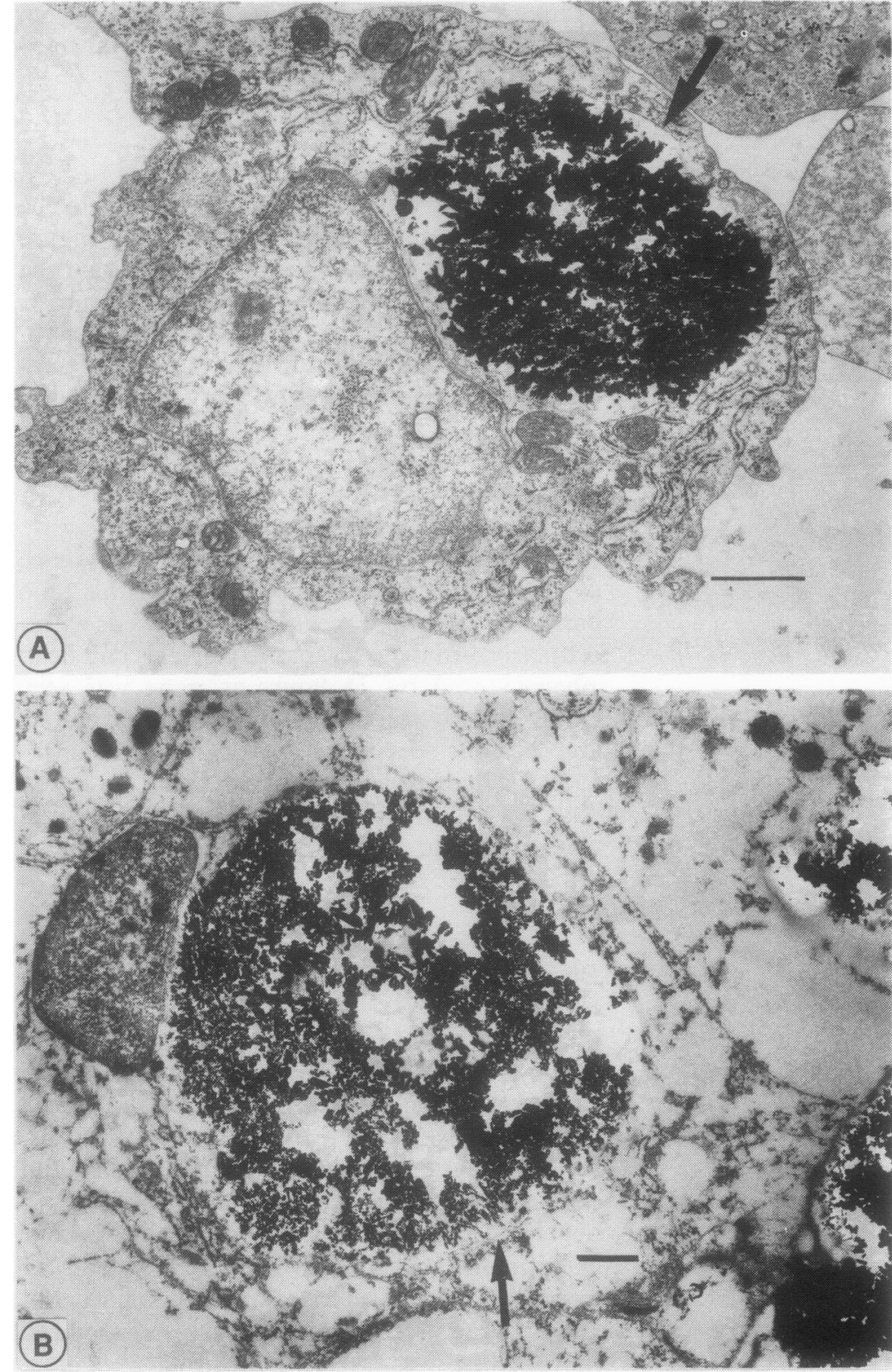

Figure 3 (A) Rat peritoneal macrophages after intraperitoneal injection of hydroxyapatte suspension at 12 hours. Bar=1 $1 \mathrm{~m}$. Phagosome membrane seen surrounding hydroxyapatite particle (arrow). (B) Rat peritoneal macrophages after intraperitoneal injection of hydroxyapatite suspension at 72 hours. Bar $=1 \mu \mathrm{m}$. Phagosome membrane seen surrounding hydroxyapatite particle (arrow).

Table 1 Comparison of peak chemiluminescence potential and area under the curve for exudate cells assayed in the phorbol myristate acetate/lucigenin system. $n=N u m b e r$ of assays performed in each group. There was no significant difference between the drug and control groups ( $\mathrm{t}$ test)

\begin{tabular}{|c|c|c|c|}
\hline & \multicolumn{2}{|c|}{ Clodronate concentration $(\mathrm{mg} / \mathrm{kg})$} & \multirow{2}{*}{$\begin{array}{l}\text { Phosphate } \\
\text { buffered } \\
\text { saline } \\
\text { (control) } \\
(n=7)\end{array}$} \\
\hline & $\begin{array}{l}10 \\
(n=4)\end{array}$ & $\begin{array}{l}30 \\
(n=4)\end{array}$ & \\
\hline $\begin{array}{l}\text { Mean (SD) potential per } 1 \times 10^{6} \text { cells } \\
\text { Mean (SD) area under curve } \\
\text { per } 1 \times 10^{6} \text { cells }\left(\mathrm{mm}^{2}\right)\end{array}$ & $\begin{array}{l}0.34(0 \cdot 31) \\
187(137)\end{array}$ & $0.38(0.22)$ & $\begin{array}{l}0 \cdot 29(0 \cdot 10) \\
158(88)\end{array}$ \\
\hline
\end{tabular}

myristate acetate stimulated, lucigenin augmented chemiluminescence. Figure 6 illustrates that of a zymosan/luminol experiment. A comparison of the two curves shows a faster response in the phorbol myristate acetate/ lucigenin system. This pattern of kinetics was also observed in the combination experiments as shown in figs 7 and 8 . Similar chemiluminescence curve shapes were obtained in combination experiments with hydroxyapatite/clodronate incubation.

\section{Effect of clodronate on chemiluminescence}

Table 1 summarises the results obtained for the phorbol myristate acetate/lucigenin system, comparing the influence of clodronate with the PBS control. The chemiluminescence output was similar in terms of potential to the control, but the area under the curve was greater at high clodronate concentrations than the control.

Effect of hydroxyapatite and hydroxyapatitel clodronate on chemiluminescence

Table 2 compares assays performed with hydroxyapatite/clodronate using hydroxyapatite as the drug free control and PBS as the apatite free control. The difference between the areas under the curve reflects the difference in curve shape, which in turn denotes a more sustained chemiluminescence response with a higher total energy output.

In addition to the results shown in the tables, there was a significant difference in both the potential and the area under the curve between $10 \mathrm{mg} / \mathrm{kg}$ clodronate and $10 \mathrm{mg} / \mathrm{kg}$ hydroxyapatite/clodronate $(p<0.01)$.

\section{Discussion}

The mechanism(s) by which bisphosphonate drugs exert their therapeutic effects in the management of osteolytic bone diseases have been extensively studied, but only partly elucidated. It is now known that, in bone, the osteoclast is the primary biological target of clodronate. ${ }^{2}$ is

In this study we have attempted to apply two methods of studying the effects of bisphosphonate on inflammatory cells. This approach was used to aid the understanding of the proposed anti-inflammatory action of clodronate ${ }^{9}$ at the cellular level. This drug has been studied extensively and used in treatment for many years and data have accumulated on its effect on hard tissue metastases, ${ }^{16}{ }^{17}$ hypercalcaemia due to malignancy, ${ }^{4}{ }^{18}$ Paget's disease of bone, ${ }^{6}$ and osteoporosis. ${ }^{19}$ This drug affects not only

Table 2 Comparison of peak chemiluminescence potential and area under the curve for exudate cells assayed in the phorbol myristate acetate/lucigenin system in the presence of hydroxyapatite. $n=N$ umber of assays performed in each group

\begin{tabular}{|c|c|c|c|c|}
\hline & \multicolumn{2}{|c|}{$\begin{array}{l}\text { Clodronate/hydroxyapatite } \\
\text { concentration (mg/kg) }\end{array}$} & \multirow{2}{*}{$\begin{array}{l}\text { Hydroxyapatite } \\
\text { (control) at } \\
84 \cdot 55 \mathrm{mg} / \mathrm{ml} \\
(\mathrm{n}=4)\end{array}$} & \multirow{2}{*}{$\begin{array}{l}\text { Phosphate } \\
\text { buffered } \\
\text { saline } \\
\text { (control) } \\
(n=7)\end{array}$} \\
\hline & $\begin{array}{l}10 \\
(n=4)\end{array}$ & $\begin{array}{l}30 \\
(n=4)\end{array}$ & & \\
\hline $\begin{array}{l}\text { Mean (SD) potential per } 1 \times 10^{6} \text { cells } \\
\text { Mean (SD) area under curve per } 1 \times 10^{6} \text { cells }\left(\mathrm{mm}^{2}\right)\end{array}$ & $\begin{array}{l}1 \cdot 16(0 \cdot 38)^{*} \dagger \\
426(258) \int\end{array}$ & $\begin{array}{l}0.83(0.45) \\
508(173) \ddagger\end{array}$ & $\begin{array}{l}0.47(0.22)^{*} \\
407(258)\end{array}$ & $\begin{array}{l}0.21(0 \cdot 10)^{*} \dagger \\
158(88) \ddagger 5\end{array}$ \\
\hline
\end{tabular}



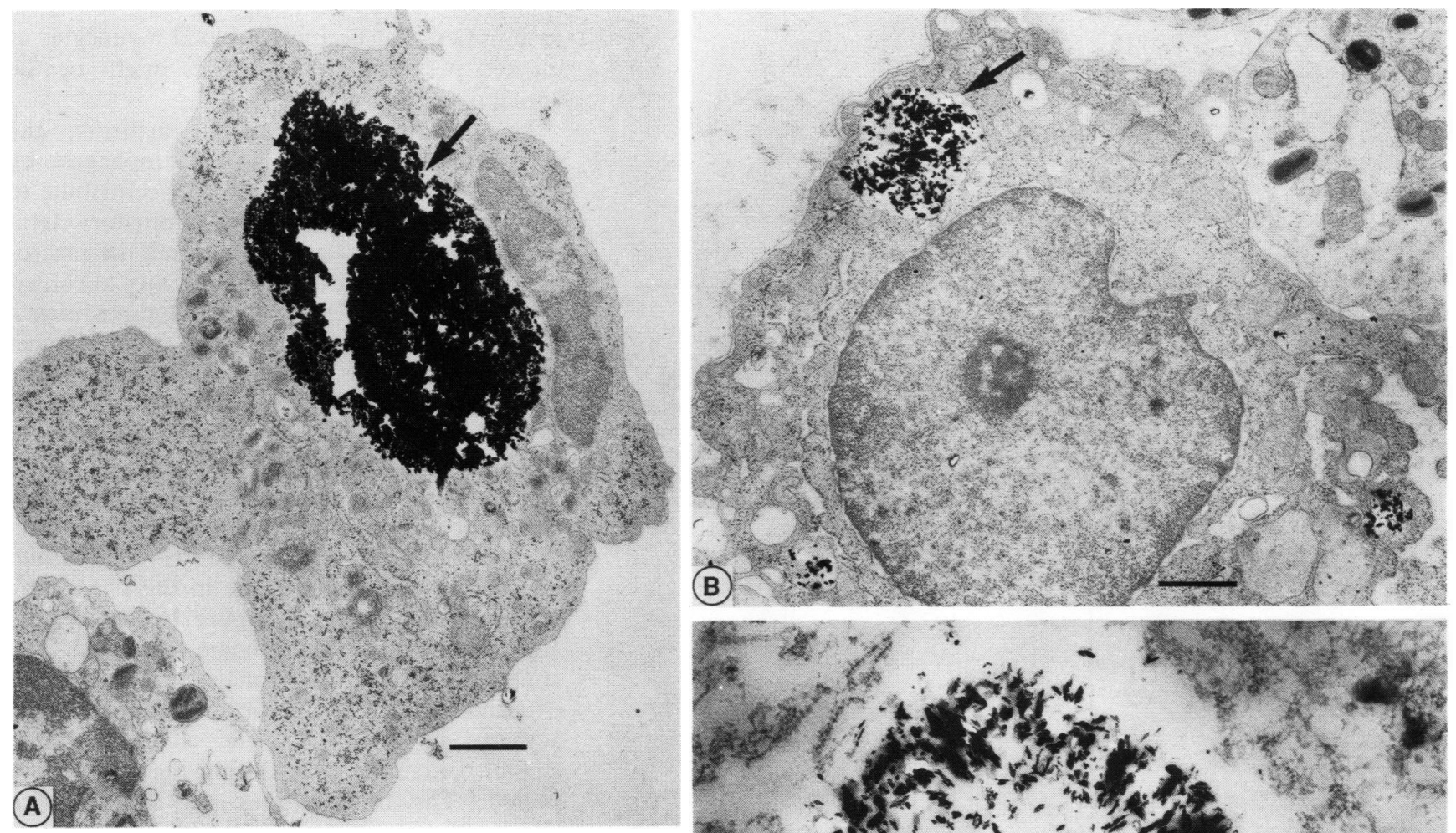

Figure 4 (A) Rat peritoneal macrophages after intraperitoneal injection of hydroxyapatite combined with clodronate at 12 hours. Bar= 1 um. Hydroxyapatite surrounded by phagosome membrane (arrow). (B) Rat peritoneal macrophages after intraperitoneal injection of hydroxy apatite combined with clodronate at 96 hours. Bar $=1 \mu \mathrm{m}$. Hydroxyapatite surrounded by phagosome membrane (arrow). (C) Typical view of advanced dissolution of hydroxyapatite particle in the presence of clodronate. $\mathrm{Bar}=500 \mathrm{~nm}$.

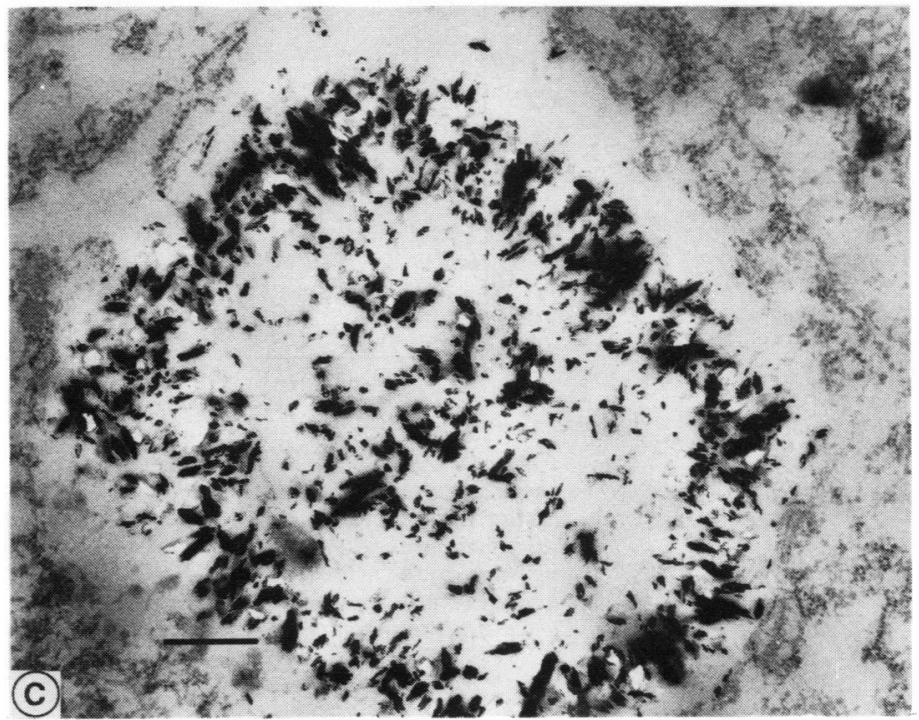

bone calcium metabolism, but has been shown to have anti-inflammatory properties in an adjuvant arthritis animal model ${ }^{9}$ and to inhibit the excretion of lysosomal enzymes in conjunction with parathyroid hormone induced resorp-

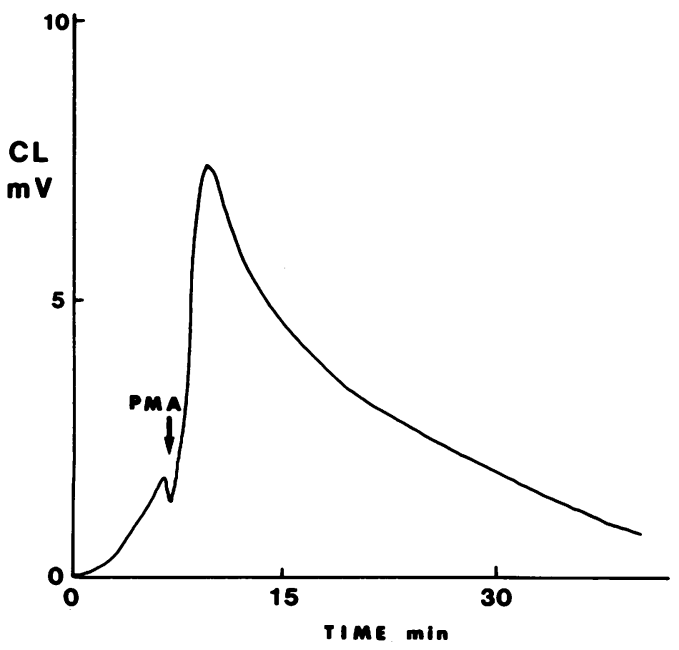

Figure 5 Phorbol myristate acetate (PMA)/lucigenin generated chemiluminescence $(C L)$ from peritoneal exudate cells after in vivo incubation with clodronate/hydroxyapatite $(10 \mathrm{mg} / \mathrm{kg})$. Lucigenin added at 0 min, phorbol myristate acetate addition shown by arrow. tion $^{20}$ and prostaglandin $\mathrm{E}_{2}{ }^{21}$ in vitro. It was of interest to determine the effect of reacting hydroxyapatite with clodronate on the subsequent phagocytosis of particles, and chemiluminescence production, by rat peritoneal macrophages.

The intracellular location of clodronate, when given to cells in culture in the absence of mineral crystals, appears to be in the cytosol..$^{22}$ As clodronate has a high affinity for hydroxyapatite, ${ }^{7}$ binding with the mineral could give it

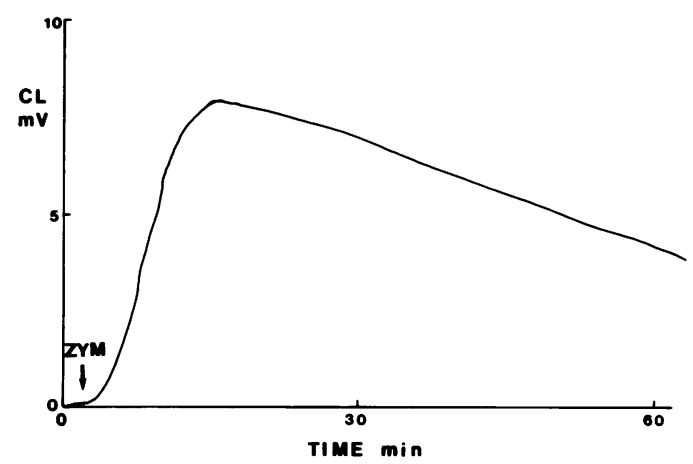

Figure 6 Zymosan (ZYM)/luminol generated

chemiluminescence $(C L)$ from peritoneal exudate cells after in vivo incubation with clodronate/ hydroxyapatite $(10 \mathrm{mg} / \mathrm{kg})$. Luminol added at 0 min, zymosan addition shown by arrow. 


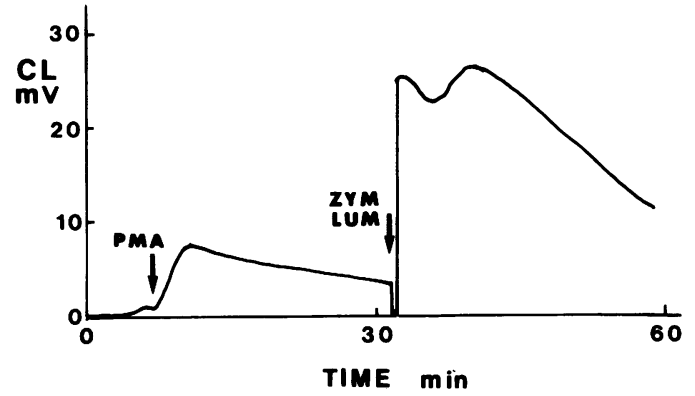

Figure 7 Phorbol myristate acetate (PMA)/lucigenin generated chemiluminescence $(C L)$ followed by zymosan (ZYM)/luminol (LUM) chemiluminescence from the same peritoneal exudate cells, after 48 hours in vivo incubation with hydroxyapatite $84.55 \mathrm{mg} / \mathrm{ml}$. Lucigenin added at $0 \mathrm{~min}$, phorbol myristate acetatel and zymosan/luminol additions shown by arrows.

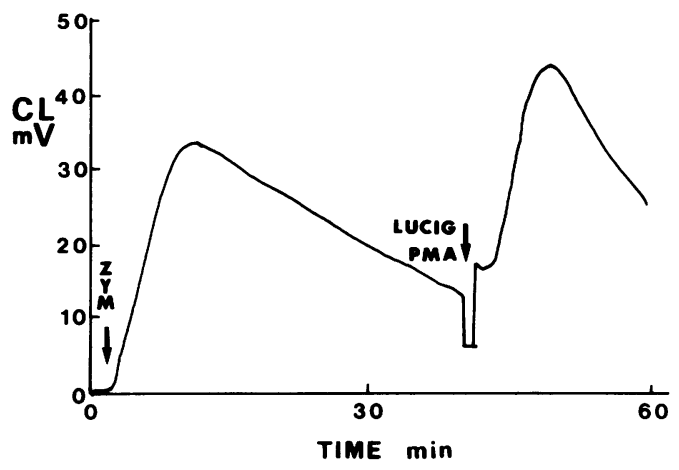

Figure 8 Zymosan (ZYM)/luminol generated chemiluminescence (CL) followed by phorbol myristate acetate/lucigenin (LUCIG) chemiluminescence from the same peritoneal exudate cells, after 48 hours in vivo incubation with hydroxyapatite $84.55 \mathrm{mg} / \mathrm{ml}$. Luminol added at 0 min, zymosan and phorbol myristate acetate/lucigenin additions shown by arrows.

an effective means of entry into the cell, once the particle is phagocytosed. Its high solubility in water, which prevents it passing through physiological membranes and thus entering the cell in large amounts (only $1-2 \%$, concluded from the kinetic study of Yakatan et $a l^{23}$ ), may facilitate its intracellular pharmacological action after having gained entry at a higher concentration in combination with the mineral.

When hydroxyapatite particles were preincubated with clodronate, phagocytosis was observed less frequently at 12 and 24 hours than for hydroxyapatite particles alone. This finding is in agreement with the impaired attachment of macrophages to bone in the presence of bisphosphonate, observed by Chambers using light microscopy. ${ }^{24}$ The hypothesis that the action of clodronate on the macrophage is mediated intracellularly is naturally valid, at least in the presence of hydroxyapatite. The observed delay in phagocytosis of the hydroxyapatite/clodronate particles may be a result of extracellular membrane irritation due to the clodronate bound to the crystal surface. Cellular toxicity has been shown towards the macrophage. ${ }^{124}$ and the osteoclast. $^{215} 25$ The results presented here may be a reflection of similar cytotoxicity. The conclusions are not surprising if these two cells types share a common bone haematopoietic precursor. ${ }^{26-29}$ Minkin and Shapiro ${ }^{30}$ have, however, voiced a word of caution about the assumption that peripheral blood monocytes or elicited peritoneal macrophages might be the actual osteoclast precursors.

In considering rheumatoid arthritis, the intracellular activation of macrophages by hydroxyapatite may inadvertently contribute to tissue damage. ${ }^{1011}$ The anti-inflammatory effect of clodronate may therefore result in macrophages being impaired in their ability to contribute to the destruction of surrounding tissues. In this in vivo model there was no doubt that the cells were able to ingest the hydroxyapatite particles whereby the drug was able to enter the cell. This can also occur in the affected joint in rheumatoid arthritis, where the macrophage is functioning as a scavenger of the crystals and other debris. ${ }^{11}$

Once phagocytosed, crystal degradation and dissolution occurs with time in the phagocytic vacuoles containing both pure hydroxyapatite and hydroxyapatite/clodronate particles. The concentration of clodronate used in this experiment did not significantly alter this lytic activity compared with the clodronate free, crystal containing cells during the observation period. The finding does not conflict with reports of some in vitro studies on mononuclear cells being capable of mineral particle phagocytosis ${ }^{24}$ or bone resorption. ${ }^{30-34} \mathrm{~A}$ fundamental difference between the above mentioned in vitro studies, which have been conducted with powdered bone, and this work is the lack of organic matrix in the hydroxyapatite used. As there is no foreign protein component in the mineral, the cells could regard this substance as non-immunogenic.

Cell morphology showed progressive degeneration with time. This seemed to be more extensive with hydroxyapatite alone than with hydroxyapatite/clodronate. Clodronate is known to be cytotoxic in the presence of calcified material, ${ }^{2}$ and yet in this experimental system good cell morphology was preserved. Throughout the study mitochondria were clearly seen in most cells, indicating the potential for metabolism.

The chemiluminescence results support those of the transmission electron microscopy experiments. Firstly, under all in vivo incubation conditions the cells were viable and capable of activation in the standardised chemiluminescence assays, the least activation occurring in the PBS control group. Secondly, the results reinforce the assumption that clodronate gains minimal access to the interior of the cell without hydroxyapatite, but does so in combination with it. Finally, it appeared that incubation with hydroxyapatite and with hydroxyapatite/ clodronate enhanced the subsequent response to stimulus, i.e. the incubation had primed the cells, a phenomenon thought to be of considerable importance in biological homeostasis. ${ }^{35}$ This effect was seen in the higher peak potential with the hydroxyapatite/clodronate group, denoting a more rapid release of energy by the cells than in the hydroxyapatite group. In contrast, the areas under the curves were similar, suggesting a more sustained response in the hydroxyapatite group. It may be relevant that clodronate is a chlorinated molecule and as 
such may be able to interact directly with chemiluminescence production. ${ }^{36}$

The finding that cell activation occurred in the two chemiluminescence systems suggests that macrophages and neutrophils were present in the exudate; this was supported by light microscopic and transmission electron microscopy examination. The consecutive activation of chemiluminescence pathways in the same cells (figs 7 and 8 ) is also suggestive of a mixed cell population but, as neutrophils in particular are able to respond strongly through the two systems, the results may also illustrate the high response levels in this exudate. This has been shown previously in human gingival crevicular exudate cells. ${ }^{37}$ In the course of this study, neither the earliest stages of phagocytosis nor the late lysis of the hydroxyapatite containing cells was seen. Further studies will be necessary to observe these stages.

This animal model allows the study of some cellular effects of the bisphosphonate drugs in vivo, and thereby facilitates the interpretation of their pharmacological action in relation to bone metabolism and anti-inflammatory function. As the hydroxyapatite crystals are taken into the cells, and clodronate thereby gains access to the cell interior, the inflammatory cell function is modified, as indicated by the chemiluminescence assays. These results support the use of clodronate in the clinical management of inflammatory bone and joint diseases.

We are grateful to Arja Korhonen and Pekka Alakuijala for their technical expertise and Eija Voutilainen, Eija Antikainen, and Alpo Pelttari for their assistance and expert advice with the electron microscopic work. The authors also thank Dr A Naukkarinen for her advice on the interpretation of the transNaukkarinen for her advice on the interpretation of the trans-
mission electron microscopy photographs. The hydroxyapatite mission electron microscopy photographs. The hydroxyapatite
was kindly donated by British Charcoals and McDonald was kindly donated by British Charcoals and McDonald (Greenock, United Kingdom) and the dichloromethylene bisphosphonate by Dr Hannu Hanhijärvi (Leiras Pharmaceuticals, Turku, Finland). Financial support was also provided by Leiras
Pharmaceuticals. This study was supported by a grant by the Pharmaceuticals. This study was supported by a grant by the
Finnish Cultural Foundation to P M Hyvönen. Our gratitude is expressed.

1 Reitsma P H, Teitelbaum S L, Bijvoet O L M, Kahn A J Differential action of the bisphosphonates (3-amino-1hydroxypropylidene)-1,1-bisphosphonate (APD) and disodium dichloromethylidene bisphosphonate $\left(\mathrm{Cl}_{2} \mathrm{MDP}\right)$ on rat macrophe-mediated bone resorption in vitro. f Clin Invest 1982; 70: 927-33.

2 Flanagan A M, Chambers T J. Dichloromethylenebisphosphonate $\left(\mathrm{Cl}_{2} \mathrm{MBP}\right)$ inhibits bone resportion through injury to osteoclasts that resorb $\mathrm{Cl}_{2} \mathrm{MBP}$-coated bone. Bone Miner 1989; 6: 33-43.

3 Jung A, Chantraine A, Donath A, et al. Use of dichloromethylene diphosphonate in metastatic bone disease. methylene diphosphonate in metastatic

4 Cohen A I, Koeller J, Davis T E, Citrin D L. Iv dichloromethylene diphosphonate in cancer-associated hypercalcemia: a phase I-II evaluation. Cancer Treatment Report 1981; 65: 651-3.

5 Jung A, van Ouwenaller C, Chantraine A, Courvoisier B. Parenteral diphosphonates for treating malignant hypercalcemia. Cancer 1981; 48: 1922-5.

6 Delmas P D, Chapuy M C, Vignon E, et al. Long term effects of dichloromethylene diphosphonate in Paget's disease of bone. f Clin Endocrinol Metab 1982; 54: 837-44.

7 Jung A, Bisaz S, Fleisch $H$. The binding of pyrophosphate and two diphosphonates by hydroxyapatite crystals. Calcif Tissue Res 1973: 11: 269-80.
8 Fleisch H. Experimental basis for the use of bisphosphonates in Paget's disease of bone. Clin Orthop 1987; 21: 72-8.

9 Flora L. Comparative antiinflammatory and bone protective effects of two diphosphonates in adjuvant arthritis. Arthritis Rheum 1979; 22: 340-6.

10 Gibilisco P A, Schumacher H R Jr, Hollander J L, Soper K A. Synovial fluid crystals in osteoarthritis. Arthritis Rheum 1985; 28: 511-5.

11 Hirsch R S, Smith K, Vernon-Roberts B. A morphologica study of macrophage and synovial cell interactions with hydroxyapatite crystals. Ann Rheum Dis $1985 ; 44: 176-80$.

12 Tsunawaki S, Nathan C F. Enzymatic basis of macrophage activation. F Biol Chem 1984; 259: 4305-12.

13 Rossi F, Bellavite P, Berton G, Grzeskowiak M, Papini E. Mechanism of production of toxic oxygen radicals by granulocytes and macrophages and their function in the inflammatory process. Pathol Res Pract 1985; 180: 136-42.

14 Dahlgren $C$, Stendahl $O$. Role of myeloperoxidase on luminol-dependent chemiluminescence of polymorphonuclear leukocytes. Infect Immun 1983; 39: 736-41.

15 Rowe D J, Hausmann E. The alteration of osteoclas morphology by diphosphonates in bone organ culture. Calcif Tissue Res 1976; 20: 53-60.

16 Elomaa I, Blomqvist C, Gröhn P, et al. Long term controlled trial with diphosphonate in patients with osteolytic bon metastases. Lancet 1983; i: 146-8.

17 Elte J W, Bijvoet O L M, Cleton F J, Van Oosterom A T, Sleebom H P. Osteolytic bone metastases in breast carcinoma pathogenesis, morbidity and bisphosphonate carcinoma, pathogenesis, morbidity and bisphosphonat

18 Jung A. Comparison of two parenteral diphosphonates in hypercalcemia of malignancy. Am F Med 1982; 72: 221-6.

19 Jowsey J, Holley $\mathrm{K}$ E. Influence of diphosphonates on progress of experimentally induced osteoporosis. $f \mathrm{Lab}$ Clin Med 1973; 82: 567-75.

20 Delaisse J-M, Eeckhout Y, Vaes G. Bisphosphonates and bone resorption: effects on collagenase and lysosoma enzyme excretion. Life Sci 1985; 37: 2291-6.

21 Felix R, Bettex J-B, Fleisch H. Effect of diphosphonates on the synthesis of prostaglandins in cultured calvaria cells. Calcif Tissue Int 1981; 33: 549-52.

22 Felix R, Guenther H L, Fleisch H. The subcellular distribution of ${ }^{14} \mathrm{C}$-dichloromethylenebisphosphonate and ${ }^{14} \mathrm{C}$-1hydroxyethylidene-1,1-bisphosphonate in cultured calvaria cells. Calcif Tissue Int 1984; 36: 108-13.

23 Yakatan G J, Poynor W J, Talbert R L, et al. Clodronate kinetics and bioavailability. Clin Pharmacol Therap 1982; 31: 402-10.

24 Chambers T J. Diphosphonates inhibit bone resorption by macrophages in vitro. F Pathol 1980; 132: 255-62.

25 Miller S C, Jee W S S. The effect of dichloromethylene diphosphonate, a pyrophosphate analogue, on bone and bone cell structure in the growing rat. Anat Rec 1979; 193 . 439-62.

26 Ash P, Loutit J F, Townsend K M S. Osteoclasts derived from haematopoietic stem cells. Nature 1980; 238: 669-70.

27 Baron R, Vignery A, Horowitz M. Lymphocytes, macrophages and the regulation of bone remodeling. In: Peck $W$ $\mathrm{A}$, ed. Bone and mineral research, Annual 2. Amsterdam: Excerpta Medica, 1983: 175-243.

28 Burger E H, van der Meer J W M, van de Gevel J S, Gribnau $J C$, Thesingh $C W$, van Furth $R$. In vitro formation of , Thesingh $C$, van Furth $R$. In vitro formation of osteoclasts from long term cuitures of bone marrow

29 Chambers T J. The cellular basis of bone resorption. Clin Orthop 1980; 151: 282-93.

30 Minkin C, Shapiro I M. Osteoclasts, mononuclear phagocytes, and physiological bone resorption. Calcif Tissue Int 1986; 39: 357-9.

31 Chambers T J. Resorption of bone by mouse peritoneal macrophages. F Pathol 1981; 135: 295-9.

32 Kahn A J, Stewart C C, Teitelbaum S L. Contact-mediated bone resorption by human monocytes in vitro. Science 1978; 199: 988-90.

33 McArthur W, Yaari A M, Shapiro I M. Bone solubilisation by mononuclear cells. Lab Invest 1980; 42: 450-6.

34 Teitelbaum S L, Stewart C C, Kahn A. Rodent peritoneal macrophages as bone resorbing cells. Calcif Tiss Int 1979; 27: 255-61.

35 Guthrie L A, McPhail L C, Henson P M, Johnston R B Jr. Priming of neutrophils for enhanced release of oxygen metabolites by bacterial lipopolysaccharide: evidence for increased activity of the superoxide-producing eznyme. $\mathcal{F}$ Exp Med 1984; 160: 1656-71.

36 Kowolik M J. The oxygen-dependent microbicidal system in human gingival crevicular neutrophils. In: Mauri C, Rizzo S C, Ricevuti G, eds. The biology of phagocytes in health and disease. Advances in the biosciences. Vol 66. Oxford: Pergamon Press, 1987, 175-83.

37 Kowolik M J, Hyvönen P M. The effect of dichloromethylene bisphosphonate on human gingival crevicular myeloperoxidase activity. Arch Oral Biol 1990; 35 (suppl): 201S-3S. 